\title{
Superoxide Dismutase-1 Induced Oxidative Stress Mediated Apoptosis in Murine Retinal Pigment Epithelial Cells
}

\author{
T.M. Viswanathan, A. Arun, D. Senthilkumar, K. Sundar, T. Kathiresan
}

\begin{abstract}
Age related macular degeneration (AMD) is a complicated ocular disease which occurs in elderly people and leads to central vision loss. The AMD generated because of overproduction of oxidative stress which leads to RPE cell death. The present study investigates whether SOD1 induced MRPE cell death based on that overexpression of SOD1 in MRPE cells which induced cell death. The SOD1 gradually increased ROS production and fragmentation of nuclei. To explore the ER stress persuaded UPR via GRP78, and CHOP, protein expression level analyses were carried out by western blotting. Together, our results represent that SOD1 could possibly produce the oxidant induced MRPE cell death.
\end{abstract}

Keywords-Age-related macular degeneration, Caspase, ER stress,

\section{INTRODUCTION}

I. Age related macular degeneration (AMD) is a leading cause of vision loss in 14 million elder populations globally in recent times; its prevalence significantly increases adult blindness in developed countries [1]. Currently, there is no effective treatment available for macular degeneration affected patients. The pathogenesis of multifactorial disease of AMD is not completely explored. Ageing itself is a most significant risk factor for AMD. Predominantly, genetic inflammation and environmental factors play a major role in progression of the disease [2]. Geographic atrophy photoreceptor support system which includes RPE, BrM and choriocapillaris [3]. This non-exudative form accounts for major AMD - associated blindness. It has been clearly hypothesized that dysfunction and apoptosis of RPE cells have a prime most role to play in the development of AMD.

The healthy RPE cells play a major role in scavenging the free radicals and reactive oxygen species (ROS) [4]. With ageing and pathological conditions, oxidative stress is caused by the imbalance between generation and elimination of ROS. The ROS production is altered by hydrogen peroxide $(\mathrm{H} 2 \mathrm{O} 2)$, singlet oxygen $(\mathrm{O} 2)$, superoxide anion (O2-) and hydroxyl radical (OH-) [5]. Recent research has shown that there is a relationship between oxidative stress and AMD [6,7]. The major organelle affected by oxidative stress is

Revised Manuscript Received on December 05, 2019

* Thadavarayan Kathiresan, Department of Biotechnology, School of Bio and Chemical Engineering, Kalasalingam Academy of Research and Education, Krishnankoil, Virudhunagar Dt., Tamilnadu PIN 626126, India.

T.M. Viswanathan, Department of Biotechnology, School of Bio and Chemical Engineering, Kalasalingam Academy of Research and Education, Krishnankoil, Virudhunagar Dt., Tamilnadu PIN 626126, India. Email: viswasonofmohan9@gmail.com

A, Arun, Department of Biotechnology, School of Bio and Chemical Engineering, Kalasalingam Academy of Research and Education, Krishnankoil, Virudhunagar Dt., Tamilnadu PIN 626126, India.

D. Senthilkumar. Department of Biotechnology, School of Bio and Chemical Engineering, Kalasalingam Academy of Research and Education, Krishnankoil, Virudhunagar Dt., Tamilnadu PIN 626126, India.

K. Sundar, Department of Biotechnology, School of Bio and Chemical Engineering, Kalasalingam Academy of Research and Education, Krishnankoil, Virudhunagar Dt., Tamilnadu PIN 626126, India. (non-exudative) is caused by progressive damage to the

mitochondria. Apart from mitochondrial response to oxidative stress, the endoplasmic reticulum (ER) also has a major role in responding to oxidative stress altered damage in epithelial cells $[8,9,10]$. Many recent studies have also explored the vital role of ER stress in mediating neuronal cell injury in the retina $[11,12]$.

In the present study, Super oxide dismutase is an enzyme that plays an important role inside the cell by scavenging the oxygen free radicals. When there is an overload of the free radicals, the over activity of SOD1 backfires and results in the further production of free radicals. This acts like a switch from antioxidant role to pro-oxidant role. Free radicals are produced more when there is high metabolic activity inside the cell. The cell death may arise due to several reasons and almost all of them can involve the over production of ROS. Therefore, suppression of oxidative stress might be a possible way for the effective treatment of AMD. The inhibition of overproduction of SOD1, which is proved to attenuate oxidative stress in our experiments on MRPE cells, is a novel and could be a promising therapeutic for the treatment of AMD.

\section{MATERIALS AND METHODS}

\section{A. Maintenance of MRPE cells}

The primary MRPE cell culture plates were maintained on IMDM medium supplemented with $10 \%$ fetal bovine serum in $60 \mathrm{~mm}$ dish. The culture medium was changed once for every three days. When the cells became confluent, they were used for the experiments or passaged. For doing a passage, the used medium in the confluent plate was discarded and $0.25 \%$ trypsin was added and monitored under a phase contrast microscope. Once the cells had reached perfect round shape, the trypsin solution was discarded and residual trypsin in the plate was inactivated by adding fresh medium. The cell sheath was peeled off by forcing the media over it by a micropipette. The suspended cells were then split up and plated on to new sterile plates. The plates were kept inside a $\mathrm{CO}_{2}$ incubator maintained at $37{ }^{\circ} \mathrm{C}$ and $5 \% \mathrm{CO}_{2}$.

\section{B.Cloning of SOD1 gene in pcDNA3.1 vector}

The total RNA isolated from MRPE cells, using Quiagen total RNA extraction kit. The first strand cDNA synthesized from template RNA by using oligo dt primer. The gene specific PCR amplified by using the gene specific primers of 5' GGATCCATGGCGATGAAAGCGGTGTGCGTG 3', 3'TTACTGCGAATCCCAATCACTTTCGAA 5'. These PCR products were cloned into TOPO cloning vector and subsequently sub cloned into pCDNA3.1 vector. The gene sequence orientation was confirmed through DNA sequencing. 


\section{Superoxide Dismutase-1 Induced Oxidative Stress Mediated Apoptosis in Murine Retinal Pigment Epithelial Cells}

\section{Transfection of SOD1 gene using Nucleofection}

The cells in the stage between the sixth and ninth passage only were used for transfection. The concentration of gene loaded vector was $568 \mathrm{ng} / \mu \mathrm{L}$. Different concentrations of SOD1 gene was used for transfection [ $2 \mu \mathrm{g}(3.52 \mu \mathrm{L}), 3 \mu \mathrm{g}(5.28 \mu \mathrm{L}), 4$ $\mu \mathrm{g}(7.04 \mu \mathrm{L})]$. The media of confluent plates were discarded and trypsinized. The cells were pelleted by centrifuging at $4000 \mathrm{rpm}$ for 3 minutes, the supernatant was discarded and the pellet was suspended in $100 \mu \mathrm{L}$ of transfection buffer (supplied by the manufacturer) and the required amount of SOD1 gene was added. The suspension was then pipetted into a nucleocuvette. The transfection program for epithelial cells was selected and the cuvette was kept inside the slot and the transfection reaction was allowed to proceed. At the end of the process, the nucleocuvette was taken out and the contents were seeded using a plastic pipette onto a fresh $60 \mathrm{~mm}$ plate containing $3 \mathrm{~mL}$ pre-warmed media. The plates were kept inside the $\mathrm{CO} 2$ incubator, left undisturbed for 24 hours and then the media was changed.

\section{Observing nuclear defragmentation using DAPI staining}

Four confluent plates were taken and three of them were transfected with increasing concentration of SOD1 gene (2 $\mu \mathrm{g}, 3 \mu \mathrm{g}, 4 \mu \mathrm{g}$ ) and the other one was kept as control. At the $24^{\text {th }}$ hour, the media in the plates were discarded and the cells were fixed using $80 \%$ methanol for $10 \mathrm{~min}$ at $4{ }^{\circ} \mathrm{C}$. Then the fixative was discarded and DAPI solution was added such that each plate harbors $15 \mu \mathrm{g}$ of DAPI and kept at $37{ }^{\circ} \mathrm{C}$ for $30 \mathrm{~min}$. At the end of $30 \mathrm{~min}$. the stain solution was discarded and the plates were washed well with 1X PBS. All the above steps were carried out in a dark environment. Then the PBS solution was discarded and the cells were visualized under a fluorescent microscope using UV light and 20X objective.

\section{E. Visualization of ROS inside the cells}

Four confluent plates were taken and three of them were transfected with increasing concentration of SOD1 gene (1 $\mu \mathrm{g}, 2 \mu \mathrm{g}, 3 \mu \mathrm{g})$ and the other one was kept as control. At the $24^{\text {th }}$ hour, the media in the plates were discarded and the cells were stained with DCFH-DA solution $(2.5 \mathrm{~mL}$ per 60

$\mathrm{mm}$ plate). The stain solution was prepared by mixing $1 \mathrm{~mL}$ of stock with $20 \mathrm{~mL}$ of serum free IMDM media. The stain solution was discarded at the end of a minute and the cells were fixed using $80 \%$ methanol. Then the cells were isualized under a fluorescent microscope using UV light and 20X objective.

\section{F. Western blot analysis}

The qualitative differences of SOD1 influenced protein expression in MRPE cells were studied using Western blot analysis. The cells were harvested at different time intervals and the harvested cells were centrifuged at $4000 \mathrm{rpm}$ for 2 min and cell pellet was washed with $1 \mathrm{x}$ PBS. Following it, $100 \mu \mathrm{L}$ of lysis buffer containing 50 mMTris- $\mathrm{HCl}, \mathrm{pH} 8.0$, $120 \mathrm{mMNaCl}, 5 \mathrm{mM}$ EDTA, $50 \mathrm{mMNaF}, 500 \mu \mathrm{g} / \mathrm{mL}$ AEBSF, $10 \mu \mathrm{g} / \mathrm{mL}$ leupeptin, $10 \mu \mathrm{g} / \mathrm{mL}$ pepstatin A, $2 \mu \mathrm{g} / \mathrm{mL}$ aprotinin, 5 mMokadaic acid and $0.2 \%$ ASB- 14 was added to the pellet. The concentration of proteins was quantified by rapid protein quantification kit, (Sigma) as per manufacturer's instruction. Fifty $\mu \mathrm{g}$ of protein was loaded to a SDS-PAGE gel and transferred to nitrocellulose membrane (Amersham bioscience, Piscataway, NJ, USA) using semi-dry western blot transfer apparatus (TE 70 PWR, Amersham Biosciences). The respective antibodies and phospho-antibodies were obtained from Cell Signalling Technology (Danver, MA, USA). The immuno reactive bands of respective proteins were visualized using enhanced chemiluminescence (Amersham bioscience).All phosphorylation and immunoreactive signals were quantified by densitometric scanner (Bio Rad, Hercules, Ca, USA).

\section{G. Statistical analysis}

All results were analyzed as the mean \pm standard error of the mean values. Statistical analysis was done by Graph pad prism 5 (Graph pad software, San Diego, CA, USA). A significance level of $\mathrm{P}$ value, less than 0.005 with a $95 \%$ confidence interval was used for control and treatment.

\section{RESULTS AND DISCUSSION}

\section{A. Morphological changes of SOD1 transfected MRPE cells}

A

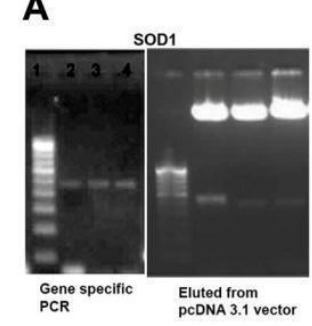

B

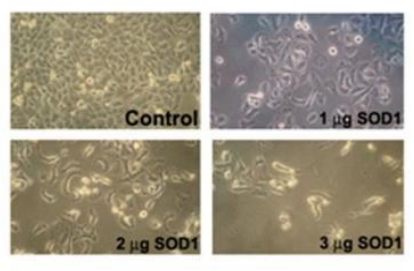

Fig.1. (a) SOD1 gene cloned into pcDNA 3.1 and (b) different concentration of SOD1 transfected in MRPE cells.

The morphological changes of SOD1 influenced MRPE cells as showed in Fig.1b. Three different concentrations $(2 \mu \mathrm{g}, 3$ $\mu \mathrm{g}, 4 \mu \mathrm{g}$ ) of SOD1 gene were transfected into MRPE cells. The number of cell death is gradually increased with the increased concentration of SOD1 gene. The shape of the cells changed to slender and elongated form and this change was observed much with the increase in concentration of the transfected gene. Increased SOD1 activity leads to the switching of its anti-oxidant property to pro-oxidant property. This causes excessive accumulation of reactive oxygen species inside the cell (Fig.1b). Thus leads to triggered cell death pathway.

\section{B. ROS production and nuclear fragmentation assay:}

Whether SOD1 induce ROS elevation in MRPE cells was evaluated by performing DCFDA assay. The different concentrations of SOD1-treated MRPE cells showed increased ROS generation at $24 \mathrm{~h}$ incubation when compared to the control. The increased concentration of SOD1-treated MRPE cells showed significantly increased ROS generation compared to control (Fig. 2). In addition, quantitative measurements of ROS production in MRPE cells are shown in Fig. 3. SOD1 induced ROS production was increased compared to the control. 

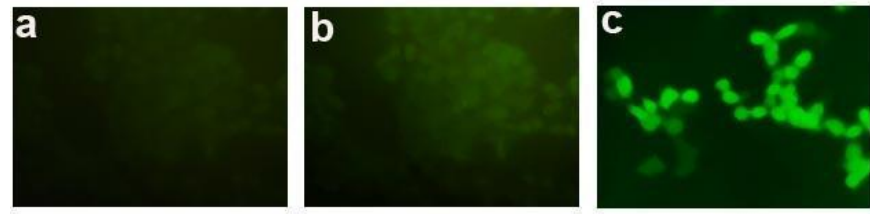

Fig.2. The ROS production is measured by $D C F H-D A$ stained in MRPE cells. (a) control, (b) $1 \square g$ SOD1(c) $3 \square g$ SOD1 transfected MRPE cells

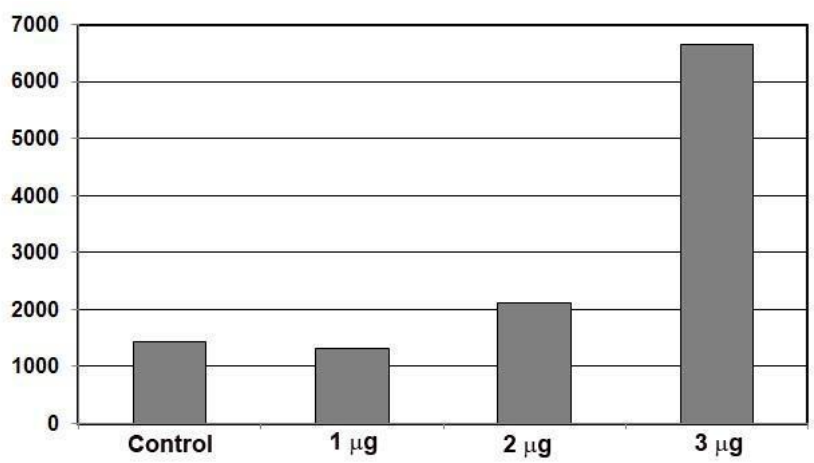

Fig.3. The quantitative analysis of ROS production in SOD1 transfected MRPE cells
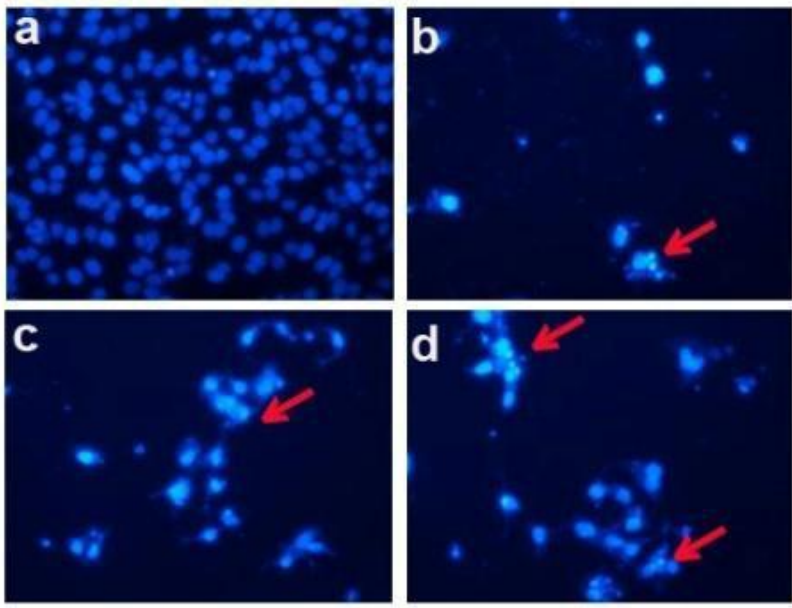

Fig.4. Nuclear fragmentation assay by DAPI staining (a) conrol, (b) $1 \mu \mathrm{g}$ SOD1(c) $2 \mu \mathrm{g}$ SOD1 transfected MRPE cells

The MRPE cells were treated with different concentrations of SOD1 were stained with DAPI as as shown in Fig.4. The nuclei of control cells were seen as evenly stained round and contact bodies. However, the SOD1 treated cells were observed in nuclei fragmentation (Fig 3c\&d). The nuclear fragmentations are clearly illustrating SOD1 significantly induced apoptosis in MRPE cells. SOD1 may be induce cell death through excessive reactive oxygen species (ROS) generation, growth factor withdrawal, and DNA damage.

\section{Western blot analysis of apoptotic proteins:}

Oxidative stress and inflammation are major risk factors for pathological development of retinal diseases and

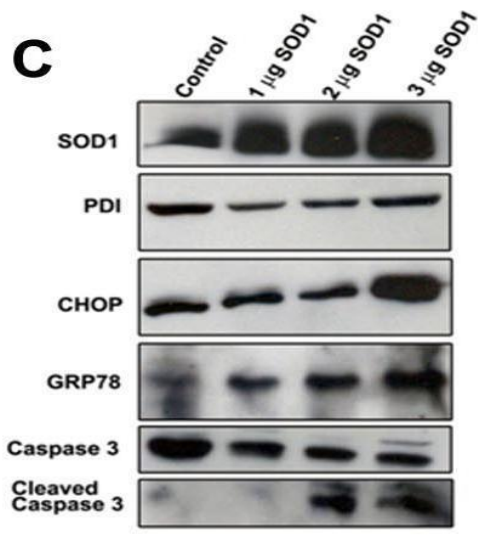

Fig .5. The expression level of SOD1 altered ER stress proteins and caspase 3 in SOD1 transfected MRPE cells vision impairment $[13,14]$. Recently, ER stress has been identified as significant risk factor that rapidly activates pathological progression of AMD [15]. The asymptomatic and irreversible nature of AMD is poor prognosis and severely hampers to development of drug. Therefore, dietary enrichment could be significantly arresting or delaying the progression of retinal disease. To understand whether SOD1 induces ER stress client proteins, we used specific antibodies that detect ER stress client proteins (Fig. 5). The GRP78/BiP and CHOP activities were drastically upregulated in SOD1 treated MRPE cells, compared to respective controls. No significant changes were observed in PDI expression in antioxidant and oxidant-treated MRPE cells. To corroborate the SOD1 induced apoptosis in MRPE cells were validated through apoptosis marker proteins as shown in Fig. 5. The cleaved caspases-3 expression was evidenced in SOD1 treated cells and was induced in SOD1 influenced cells. Prolonged ER stress triggers pro-apoptotic signaling through GRP78 and CHOP. CHOP and Bcl-2 are the down streaming molecules which are initiated by PERK and ATF6 and execute of cell death pathway. Our results show that SOD1 moderately increased CHOP expression. Hence the selective induction of CHOP can be attributed to ER stress [16].

The overexpression of SOD1 in mouse retinal pigment epithelial cells caused apoptosis. SOD1 proved that reactive oxygen species production alone is not the mechanism by which apoptosis is enacted. SOD1 interacts with other cellular proteins to make this event happen. Accordingly, ER stress proteins get activated in due course. This gives an insight that ER stress proteins can be targeted by chemical drugs to suppress the cell death caused by increased SOD1 activity. These results can be applied to treat the condition of age-related macular degeneration.

\section{REFERENCES}

1. L. S. Lim, P. Mitchell, J. M. Seddon, F. G. Holz, and T. Y. Wong "Age-related macular degeneration". Lancet, (2012), 379, 1728-1738.

2. A. Swaroop, E. Y. Chew, C. B. Rickman, and G. R. Abecasis, "Unraveling a multifactorial late-onset disease: from genetic susceptibility to disease mechanisms for age-related macular degeneration". Annu Rev Genomics Hum Genet (2009), 10, 19-43.

3. A. Takahashi, S. Ooto, K. Yamashiro, A. Oishi, H. Tamura, H Nakanishi, N. Ueda-Arakawa, A. Tsujikawa, and N. Yoshimura, "Photoreceptor Damage and Reduction of Retinal Sensitivity Surrounding Geographic Atrophy in Age-Related Macular Degeneration". Am J Ophthalmol, (2016), 168, 260-268.

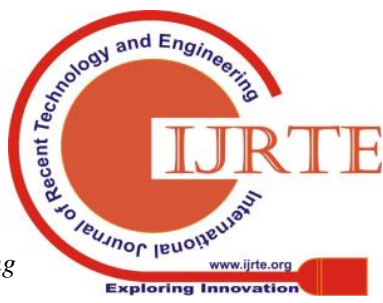




\section{Superoxide Dismutase-1 Induced Oxidative Stress Mediated Apoptosis in Murine Retinal Pigment Epithelial Cells}

4. A. King, E. Gottlieb, D. G. Brooks, M. P. Murphy, and J. L. Dunaief, "Mitochondria-derived reactive oxygen species mediate blue light induced death of retinal pigment epithelial cells, Photochem. Photobiol, (2004), 79(5), 470-475.

5. J. L. Dunaief, T. Dentchev, G. S. Ying, and A. H. Milam, "The role of apoptosis in age-related macular degeneration", Arch.Ophthalmol, (2002), 120(11), 1435-1442.

6. B. S. Winkler, M. E. Boulton, J. D. Gottsch, and P. Sternberg, "Oxidative damage and age-related macular degeneration", Mol. Vis, (1999), 5, 32.

7. P. Yang, J. J. Peairs, R. Tano, and G. J. Jaffe, "Oxidant-mediated Akt activation in human RPE cells", Invest.Ophthalmol. Vis. Sci., (2006), 47(10), 4598-4606.

8. S. He, J. Yaung, Y. H. Kim, E. Barron, S. J. Ryan, and D. R. Hinton, "Endoplasmic reticulum stress induced by oxidative stress in retinal pigment epithelial cells", Graefes. Arch. Clin. Exp. Ophthalmol, (2008), 246(5), 677-683

9. B. Karthikeyan, A. Arun, L. Harini, K. Sundar, T. Kathiresan, "Role of $\mathrm{ZnS}$ Nanoparticles on Endoplasmic Reticulum Stress-mediated Apoptosis in Retinal Pigment Epithelial Cells". Biol Trace Elem Res. (2016), 170, 390-400.

10. K. Bose, H. Lakshminarasimhan, K. Sundar, T. Kathiresan, "Cytotoxic effect of $\mathrm{ZnS}$ nanoparticles on primary mouse retinal pigment epithelial cells". Artif Cells Nanomed Biotechnol, (2019), 44, 1764-73.

11. B. Karthikeyan, L. Harini, V. Krishnakumar, V. R. Kannan, K. Sundar, T. Kathiresan, "Insights on the involvement of (-)-epigallocatechin gallate in ER stress-mediated apoptosis in age-related macular degeneration". Apoptosis, (2017), 22, 72-85.

12. T. Adachi, H. Yasuda, S. Nakamura, T. Kamiya, H. Hara, and T. Ikeda, "Endoplasmic reticulum stress induces retinal endothelial permeability of extracellular-superoxide dismutase", Free. Radical. Res, (2011), 45(9), 1083-1092.

13. M. A. Brantley, M. P. Osborz, B. J. Sanders, K. A. Rezaei, P. Lu, C. Li, G. L. Milne, J. Cai, and P. Sternberg, "Plasma biomarkers of oxidative stress and genetic variants in age-related macular degeneration". Am J Ophthalmol, (2012), 153, 460-7.

14. J. Yao, X. Liu, Q. Yang, M. Zhuang, F. Wang, X. Chen, H. Hang, W. Zhang, and Q. Liu, "Proteomic analysis of the aqueous humor in patients with wet agerelated macular degeneration". Proteomics Clin Appl, (2013), 7, 550-60

15. A. Salminen, A. Kauppinen, J. M. Hyttinen, E. Toropainen, and K. Kaarniranta, "Endoplasmic reticulum stress in age-related macular degeneration: trigger for neovascularization". Mol Med, (2010), 16, $535-42$.

16. A. L. Huber, J. Lebeau, P. Guillaumot, V. Pétrilli, M. Malek, J. Chilloux, F. Fauvet, L. Payen, A. Kfoury, T. Renno, E. Chevet, an S. N. Manié, "p58IPK-Mediated Attenuation of the Proapoptotic PERK-CHOP Pathway Allows Malignant Progression upon Low Glucose”. Molecular Cell, (2013). 49, 1049-1059.

\section{AUTHORS PROFILE}

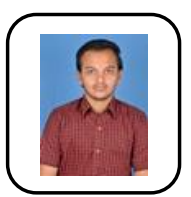

T.M. Viswanathan, is a $\mathrm{PhD}$ Scholar in Kalasalingam Academy of Research and Education.

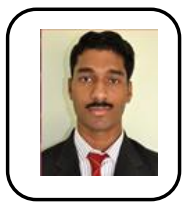

A. Arun, is a $\mathrm{PhD}$ Scholar Manonmaniam Sundaranar University, Tirunelveli.

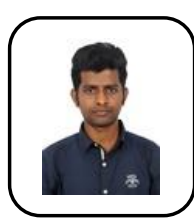

D. Senthil Kumar, is a Post-Doctoral Research fellow in Kalasalingam Academy of Research and Education.

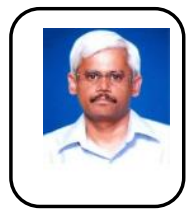

K. Sundar, currently works at the Professor-Dean, Department of Biotechnology, Kalasalingam Academy of Research and Education.

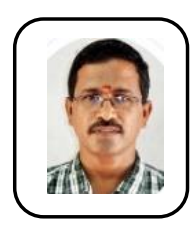

Thandavarayan Kathiresan, currently works at the Professor, Department of Biotechnology, Kalasalingam Academy o Research and Education. 